\title{
Activation of Pulmonary Dendritic Cells and Th2-Type Inflammatory Responses on Instillation of Engineered, Environmental Diesel Emission Source or Ambient Air Pollutant Particles in vivo
}

\author{
Gillina F.G. Bezemer ${ }^{a}$ Stephen M. Bauer ${ }^{b}$ Günter Oberdörster ${ }^{c, e}$ \\ Patrick N. Breysse $^{f}$ Raymond H.H. Pieters ${ }^{a}$ Steve N. Georas ${ }^{b}$, d, e \\ Marc A. Williams ${ }^{\text {b, }}$, e \\ ammunotoxicology Institute for Risk Assessment Sciences, Utrecht University, Utrecht, The Netherlands; \\ ${ }^{b}$ Division of Pulmonary and Critical Care Medicine, ' Division of Respiratory Biology and Toxicology, ${ }^{d}$ Lung Biology \\ and Disease Program, ${ }^{e}$ Department of Environmental Medicine, University of Rochester School of Medicine and \\ Dentistry, Rochester, N.Y., and ${ }^{f}$ Department of Environmental Health Sciences, Johns Hopkins University, \\ Bloomberg School of Public Health, Baltimore, Md., USA
}

\section{Key Words}

Innate immunity · Allergic immunity • Dendritic cell • Lung Inflammation - Immunotoxicology $\cdot$ Toxicology • Particulate matter $\cdot$ Nanoparticles

\begin{abstract}
The biological effects of acute particulate air pollution exposure in host innate immunity remain obscure and have relied largely on in vitro models. We hypothesized that single acute exposure to ambient or engineered particulate matter (PM) in the absence of other secondary stimuli would activate lung dendritic cells (DC) in vivo and provide information on the early immunological events of PM exposure and DC activation in a mouse model naïve to prior PM exposure. Activation of purified lung DC was studied following oropharyngeal instillation of ambient particulate matter (APM). We compared the effects of APM exposure with that of dieselenriched PM (DEP), carbon black particles (CBP) and silver nanoparticles (AgP). We found that PM species induced variable cellular infiltration in the lungs and only APM exposure induced eosinophilic infiltration. Both APM and DEP activat-
\end{abstract}

\section{KARGER}

(C) 2010 S. Karger AG, Basel

Fax +4161306 1234

E-Mail karger@karger.ch

www.karger.com
Accessible online at: www.karger.com/jin ed pulmonary DC and promoted a Th2-type cytokine response from naïve $C D 4+T$ cells ex vivo. Cultures of primary peribronchial lymph node cells from mice exposed to APM and DEP also displayed a Th2-type immune response ex vivo. We conclude that exposure of the lower airway to various PM species induces differential immunological responses and immunomodulation of DC subsets. Environmental APM and DEP activated DC in vivo and provoked a Th2 response ex vivo. By contrast, $C B P$ and $A g P$ induced altered lung tissue barrier integrity but failed to stimulate CD4+ T cells as effectively. Our work suggests that respirable pollutants activate the innate immune response with enhanced DC activation, pulmonary inflammation and Th2-immune responsiveness.

Copyright $\odot 2010$ S. Karger AG, Basel

\section{Introduction}

The immune pathology of asthma is defined in part by airway hyperresponsiveness and a deregulated pattern of Th2 cytokine release including interleukin (IL)-4, IL-5 and IL-13 [1-4]. Several studies also support a Th1 com- 
ponent (e.g. secretion of interferon- $\gamma$, IFN- $\gamma$ ) in asthma $[5,6]$. Environmental cues such as ambient particulate matter (APM) and diesel exhaust particles (DEP, an emission source $\mathrm{PM}$ ) stimulate adaptive and innate immunity in asthma [3,5-9]. The modulation of lung innate immunity by biologically, chemically or structurally disparate particulate matter (PM) species that can breach the airway barrier and interact with host immunity is important. Environmental PM is a complex mixture of particles with varying properties. How the properties of exposure to PM contribute to altered early pulmonary immune responses and dendritic cell (DC) activation in vivo are unclear but may be attributable to cellular contact-dependent particle size and surface area of the PM species, elemental and hydrocarbon constitution and an inherent ability to differentially promote oxidative stress and acute inflammation [10-14].

The airway wall is a biologically complex cellular barrier that is considered a major arm of the innate immune system, and maintains the lung as an immune-privileged organ [15]. Interdigitated throughout the respiratory epithelium are specialized macrophages and professional antigen-presenting DC subsets [15-17]. Airway inflammation in allergic asthma reflects an aberrant immune response against otherwise harmless inhaled allergens. Although DCs are regularly distributed throughout the bronchial epithelium and parenchyma, little is known about how inhaled environmental exposures affect the activation of DCs. We have shown that APM, environmental DEP or a common allergen (e.g. ragweed extract) instructs 'non-classic' DC maturation enabling them to stimulate a complex pattern of Th1- and Th2-associated responses $[6,12,18,19]$. The exact location of where DCs sample respirable antigen in the lung remains ill-defined $[15,16]$, although it is known that DC serve a key role in the immune pathology of allergic asthma [20-22].

The lung is known to benefit from the functions of two major subsets of DC, termed conventional myeloid DC (mDC), that express moderate to high levels of both $\mathrm{CD} 1 \mathrm{c}+$ and $\mathrm{CD} 11 \mathrm{~b}+$, and a second subpopulation, termed plasmacytoid DC ( $\mathrm{pDC}$ ), that display cell-surface expression of PDCA-1 and low levels of CD11c [23-27]. Studies exploring the role of DC activation and allergic risk in asthma development have focused on the adjuvant potential of PM to induce allergic sensitization to a coadministered antigen-like ovalbumin (OVA) or house dust mite $[6,12,18,28-32]$. Often high and repeated doses of PM exposure are used that also induce tissue damage and general airway inflammation.

Activation of Lung Dendritic Cells by Particulate Matter in vivo
In this report we hypothesized that single acute exposure to ambient or engineered PM in the absence of an additional immune adjuvant would promote activation of lung DC in vivo, particularly at the levels of differential markers of pulmonary inflammation, particle uptake in the lung and activation of DC in vivo. We have previously conducted detailed in vitro studies of the effects of PM on human and murine $\mathrm{mDC}[5,6,12,19]$. Until now, we have not tested the acute immunological and inflammatory effects of APM in vivo to model the immunological effects of an acute exposure to PM in naïve mice. To test our hypothesis, we used oropharyngeal aspiration as a route of PM delivery in a relevant mouse model. Several groups, including ours, have focused recent attention on the possibility that respirable ambient pollutants behave as immune adjuvants and can exacerbate preexisting airways disease in response to aeroallergen and house dust exposure or in response to pulmonary viral infections.

The reasons for using a mouse model to study alterations in DC functional activation on acute exposure to PM species included the notion that airway DC are the key initiators of the allergic innate immune response in the lung in murine models of asthma [12, 33-35]. We have compared PM species known to have adverse health effects in human subjects including ambient environmental (APM) and emission source (DEP) pollutant particles with commercially available carbon black particles (CBP) and engineered silver nanoparticles (AgP) in vivo. This study allowed us to compare complex ambient PM mixtures (APM and DEP) with noncomplex and nonambient purified particulates (CBP and $\mathrm{AgP}$ ) and to study the acute functional and mechanistic responses of primary lung DC subsets in vivo and ex vivo.

\section{Materials and Methods}

\section{Animal Models}

Helicobacter pylori-free and nonallergic wild-type C57BL/6J mice and OTII. 2 mice which carry a transgenic T cell receptor gene rearrangement specific for OVA on the C57BL/6 genetic background [36] were both obtained from The Jackson Laboratory (Bar Harbor, Me., USA). All animal studies were performed in compliance with the University of Rochester, School of Medicine and Dentistry's Committee on Animal Research.

Particle Collection and Preparation

Particles used in this study were concentrated environmental APM collected from Baltimore City air and environmental DEP collected from the diesel exhaust plenums of the Baltimore Harbor Tunnel (using a cyclone collector with a cut-size of $0.3 \mu \mathrm{m}$ that collected particles greater than $0.1-0.3 \mu \mathrm{m}$ in aerodynamic diameter) as described $[5,6,19]$. Environmental DEP was collected at 
Fig. 1. Difference in agglomeration state of PM species by SEM. Microscopic appearance of the AgP, DEP, APM and CBP particles used in these studies. Original magnification, $\times 400$.
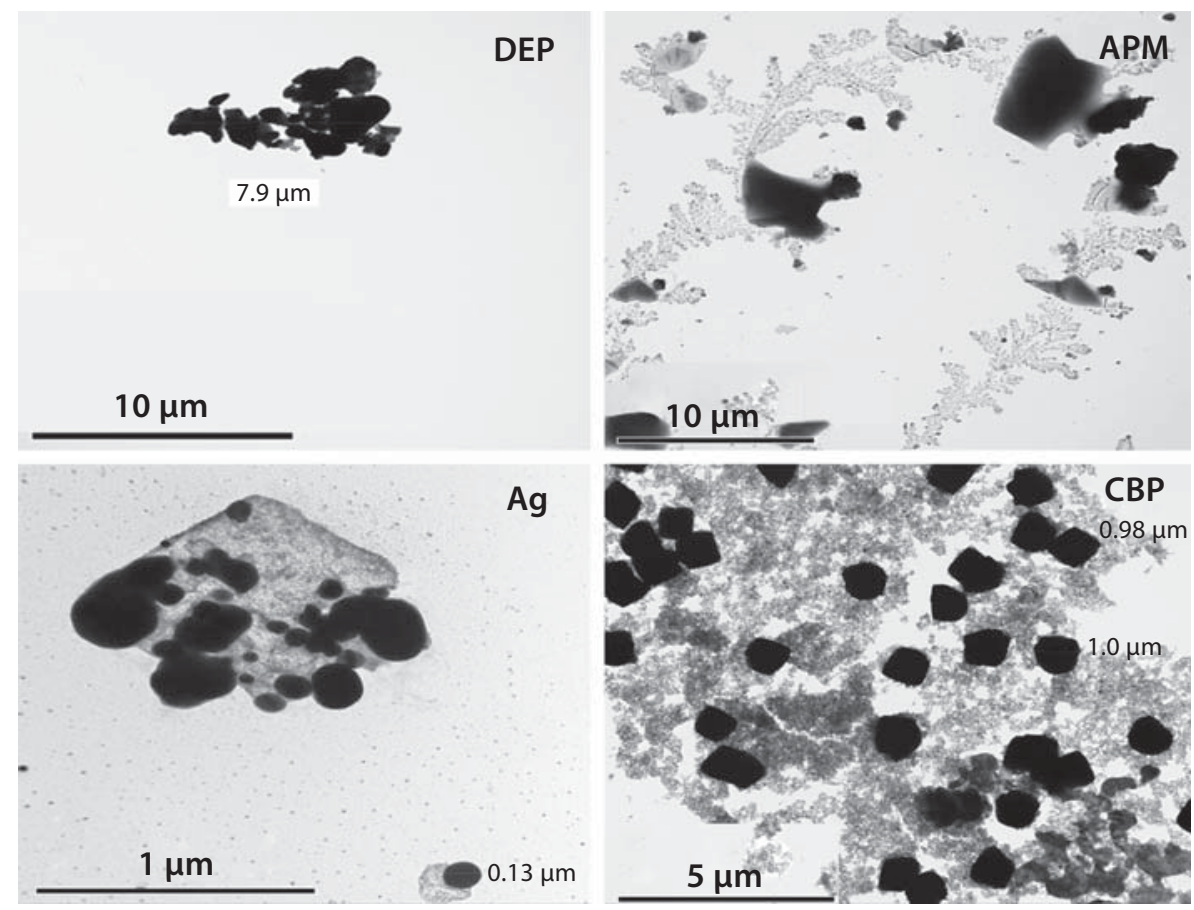

Table 1. Characterization of particles used in acute exposure study

\begin{tabular}{|c|c|c|c|c|}
\hline & $\begin{array}{l}\text { Measured } \\
\text { particle size } \\
\text { Z-average, nm }\end{array}$ & $\begin{array}{l}\text { Cell-free ROS } \\
\text { equivalent } \mathrm{H}_{2} \mathrm{O}_{2} \\
\mu \mathrm{M} / 50 \mu \mathrm{l}\end{array}$ & $\begin{array}{l}\text { LPS } \\
\text { EU/50 } \mu \mathrm{l}\end{array}$ & $\begin{array}{l}\text { Degree of } \\
\text { agglomeration }\end{array}$ \\
\hline DEP & $300-500$ & 0.28 & 0.099 & moderate/high \\
\hline AgP & $40-300$ & 27.9 & 0.006 & low/moderate \\
\hline APM & 400 & 7.55 & 0.001 & high \\
\hline $\mathrm{CBP}$ & 300 & 1.69 & 0.182 & moderate \\
\hline
\end{tabular}

A series of measures were taken and stated as the unit of measure present in $50 \mu \mathrm{l}$ of saline suspension, which represented the volume of bolus PM suspension for oropharyngeal instillation of mice. The hydrodynamic size diameters of the PM species suspended in saline (at the nanometer scale) were determined by dynamic light scattering (also known as photon correlation spectroscopy or quasi-elastic light scattering) using a ZetaSizer Nano ZS device (Malvern Instruments Ltd., UK). Noncellular (cell-free) ROS activity in the PM suspensions was measured using a standard assay (Applied Nanoscience). Levels of endotoxin were detected by a standard limulus amebocyte lysate assay. The degree of agglomeration was estimated by electron micrograph analysis (see also fig. 1). LPS = Lipopolysaccharide; EU = endotoxin units. a flow rate of $1.0 \mathrm{~m}^{3} / \mathrm{min}$ from the section of the tunnel used by truck traffic, creating a PM sample enriched in diesel particles and collected over a period of 1 month. The effects of APM and DEP were compared with laboratory-generated CBP obtained from Degussa as Printex 90 and commercially available silver particles (AgP, Applied Nanoscience). The characteristics of each PM species were all defined (table 1). The hydrodynamic size diameters of the PM species (at the nanometer scale) were determined by dynamic light scattering (also known as photon correlation spectroscopy or quasi-elastic light scattering) using a ZetaSizer Nano ZS device (Malvern Instruments Ltd., UK) and scanning electron microscope (SEM) images indicated their agglomeration state (fig. 1). For SEM analysis, particles were suspended in methanol with one drop placed on an SEM stub and desiccated for $24 \mathrm{~h}$ prior to imaging. Levels of lipopolysaccharide (endotoxin) were detected by Limulus amebocyte lysate assay, and found to be $<50 \mathrm{pg} / 100 \mu \mathrm{g}$ of suspended PM. Levels of endotoxin were very low and at doses used for in vitro studies failed to activate either human or mouse DC $[5,6,19]$.

\section{Assay of Cell-Free Reactive Oxygen Species Generation by PM} Species

Noncellular reactive oxygen species (ROS) equivalent activity in PM suspensions was measured using a standard assay. In this assay, the intrinsic free radical electron-inducing capacity of PM species in phosphate buffer is assessed for their ability to induce fluorescent dichlorofluorescein (DCFH) oxidation by radical electrons from its nonfluorescent precursor DCFH-diacetate (Calbiochem-Novabiochem, San Diego, Calif., USA). The radical electrons are transferred from the PM species surface by the enzyme horseradish peroxidase. DCFH is thus used as a probe for 
reactive oxygen species production in a cell-free system by ambient, engineered or emission-source particulate pollutants. The resultant 'respiratory burst' is quantified by measuring the oxidation of DCFH-diacetate to fluorescent DCFH with a fluorometer (with an excitation wavelength set at $486 \mathrm{~nm}$ and emission wavelengths from 570 to $700 \mathrm{~nm}$, Barnstead/Turner International, Model FM 109). Data are then expressed as hydrogen peroxide $\left(\mathrm{H}_{2} \mathrm{O}_{2}\right)$ equivalents based on a linear fit standard curve of $\mathrm{H}_{2} \mathrm{O}_{2}$ at the micromolar level and determination of unknown values against the equation of the line (table 1). Standards and unknown PM samples were quantified in duplicate and the mean reading taken.

\section{Experimental Design}

We conducted four independent experiments at intervals of 1 week apart whereby pools of 4 mice per experimental group of five groups of mice (20 mice per independent experiment) were dosed with a single suspension of APM, DEP and CBP (all at $25 \mu \mathrm{g}$ ) or $10 \mu \mathrm{g} \mathrm{AgP}$ in $50 \mu \mathrm{l} 0.9 \% \mathrm{w} / \mathrm{v}$ saline vehicle or $50 \mu \mathrm{l}$ saline alone directly into the lung by oropharyngeal aspiration under anesthesia. In four independent experiments, a total of 80 mice were studied. PM suspensions were cup-horn sonicated for 15-second intervals over a period of $10 \mathrm{~min}$, vortexed vigorously for $5 \mathrm{~min}$, and immediately delivered to the mice $[37,38]$. Mice were rested for 24 $\mathrm{h}$, prior to immunological end-point measures.

\section{Measurement of Cellular and Biochemical Parameters in}

\section{Bronchoalveolar Lavage Fluid (BALF)}

Mice were euthanized $24 \mathrm{~h}$ after exposure with an overdose of sodium pentobarbital (200 mg/kg body weight, i.p.) and exsanguinated by cardiac puncture. Lungs were lavaged in situ 4 times with each $1 \mathrm{ml}$ of pyrogen-free $0.9 \% \mathrm{w} / \mathrm{v}$ normal saline. The cells were pelleted at $300 \mathrm{~g}$ for $10 \mathrm{~min}$ at $4^{\circ} \mathrm{C}$. Supernatants were discarded except from the first lavage, which was retained and assayed for biochemical assays. Lung epithelial permeability was assessed by total protein levels in the supernatant using a bicinchoninic acid assay (Sigma, St. Louis, Mo., USA). Cytotoxicity induced by instilled PM was determined by assaying lactate dehydrogenase (LDH) activity and macrophage activation measured by assaying for $\beta$-glucuronidase activity using commercially available materials (Sigma). The BALF cell pellets were resuspended in $2 \mathrm{ml}$ of $0.9 \% \mathrm{w} / \mathrm{v}$ normal saline. Total cell numbers and viability were assessed by trypan blue exclusion. For differential cell counts, $5 \times 10^{4}$ cells per BALF sample were cytospinned for $5 \mathrm{~min}$ at $600 \mathrm{rpm}$ using a Shandon Southern Cytospin, then stained with a Diff-Quik staining set (Baxter Scientific, Edison, N.Y., USA). A total of 300 cells were counted from each slide for differential cellular categorization. To determine the phagocytic ability of macrophages, inverted light microscope images were made from the stained cytospinned BALF cells.

\section{Purification and Enrichment for Lung DC Subsets}

Lungs were removed from the pulmonary cavity and pooled per experimental group for further processing to isolate DC subsets as previously described in detail $[12,39]$. For this study, groups of 4 mice were euthanized by i.p. injection of $200 \mathrm{mg} / \mathrm{kg}$ sodium pentobarbital and cervical dislocation, consistent with University of Rochester IACUC mouse protocols and recent guidelines on euthanasia from the American Veterinary Medical Association. The procedures described in detail before were then followed $[12,39]$. To enrich for $\mathrm{pDC}$ and $\mathrm{mDC}$ subpopulations from the macrophage-depleted lung homogenates, we first selected the $\mathrm{pDC}$ fraction by direct isolation of PDCA-1-expressing pDCs (Miltenyi Biotec), followed by isolation of the CD11c+ $\mathrm{mDC}$ fraction according to a commercial protocol (Miltenyi Biotec).

\section{Phenotypic Analysis of DC Populations by Flow Cytometric} Analysis

We used multiparameter flow cytometry to measure the expression of function-associated molecules by purified DC as described [6]. DC preparations were then stained with the following FITC or PE fluorochrome-conjugated mAbs (BD Pharmingen): anti-MHC class II-PE (polymorphic Ia/Ie determinants), antiCD11b-PE, anti-CD11c-PE, anti-CD54-PE, anti-CD80-PE, antiCD86-PE, and anti-CD40-PE. In assays where the purity of lung DC subpopulations required confirmation, we used anti-CD45R/ B220-PE (BD Pharmingen), anti-PDCA-1-FITC (clone JF051C2.4.1; Miltenyi Biotec), anti-Gr1-PE (BD Pharmingen) and anti-CD11c-APC (clone N418; Miltenyi Biotec). Samples were fixed in $2 \% \mathrm{v} / \mathrm{v}$ paraformaldehyde in FACS buffer prior to analysis on a FACSCalibur flow cytometer using CellQuest 3.1 software (BD Biosciences). For the analysis of forward angle light scatter, side angle light scatter, and cell surface receptor expression, data were acquired in real time as percent positive-expressing cells and geometric mean fluorescence intensity (MFI).

\section{Primary Lymph Node Cell ( $p L N C)$ Assay and Cytokine \\ Repertoire Analysis}

To measure the immunological response of activated $\mathrm{T}$ cells by the putative migrating pulmonary DC, the draining peribronchial and mediastinal lymph nodes were isolated, and a single mononuclear cell suspension was prepared in complete RPMI 1640 culture medium. Enriched pLNCs were seeded into 24-well culture plates at a density of $2.5 \times 10^{5}$ cells/well in $1 \mathrm{ml}$ and cultured with and without concanavalin A (ConA, $10 \mu \mathrm{g} / \mathrm{ml}, 48 \mathrm{~h}$ ). Cell-free supernatants were prepared by centrifugation at $500 \mathrm{~g}$, $10 \mathrm{~min}$, room temperature and stored at $-86^{\circ} \mathrm{C}$ until assayed for Th1 (IFN- $\gamma$ ) and Th2 (IL-4, IL-5) type cytokines by multiplex cytokine array (Biorad/Bioplex system). Data were recorded as picograms cytokine $/ 10^{6} \mathrm{pLNC}$.

Cocultures of Allogeneic CD4+T Cells with Subpopulations of $m D C$ and $p D C$

To determine the stimulatory function of DC, a coculture assay was designed, in which purified $\mathrm{mDC}$ and $\mathrm{pDC}$ were OVA pulsed $(50 \mu \mathrm{g} / \mathrm{ml}, 4 \mathrm{~h})$, washed and cocultured with highly purified naïve CD4+ CD62L+ T cells [6] of transgenic OT-II.2 mice expressing the $\mathrm{T}$ cell receptor specific for $\mathrm{OVA}_{323-339}$ and $\mathrm{MHC}$ class II- $A^{b}$ as described $[6,36]$. To assay for spontaneous activation, DC and purified CD4+ T cells were cultured alone at $5 \times$ $10^{4}$ and $2.5 \times 10^{5}$ cells $/$ well $/ \mathrm{ml}$, respectively. In the coculture assay, the same numbers of DC or CD4+CD62L+ T cells were used (for a ratio of $\mathrm{DC}$ to $\mathrm{T}$ cells of 1:5) in triplicate wells for 4 days at $37^{\circ} \mathrm{C} / 5 \% \mathrm{CO}_{2}$. To study how in vivo PM exposure alters the ability of DC to induce T cell proliferation, we used a standard BrdU assay (Roche Applied Science) as described [6]. Cell-free culture supernatants were also collected and stored at $-86^{\circ} \mathrm{C}$ until assayed for Th1 (IFN- $\gamma$, IL-2, IL-6, tumor necrosis factor- $\alpha$, IL-12p40) and Th2 (IL-5, IL-13 and IL-10) cytokine production using stan- 
Fig. 2. Total cell quantitation in BALF harvested from PM-exposed mice. Shown here are the mean total cell counts $\times 10^{6}$ infiltrating the lung as determined by cytological examination of cytospinned cell preparations (a). Data are shown as the arithmetic mean of 16-19 measurements $\pm \mathrm{SD}$. Also shown is a cytological BALF preparation of a saline-only-exposed mouse (b). The majority of the cells were found to be macrophages (b).
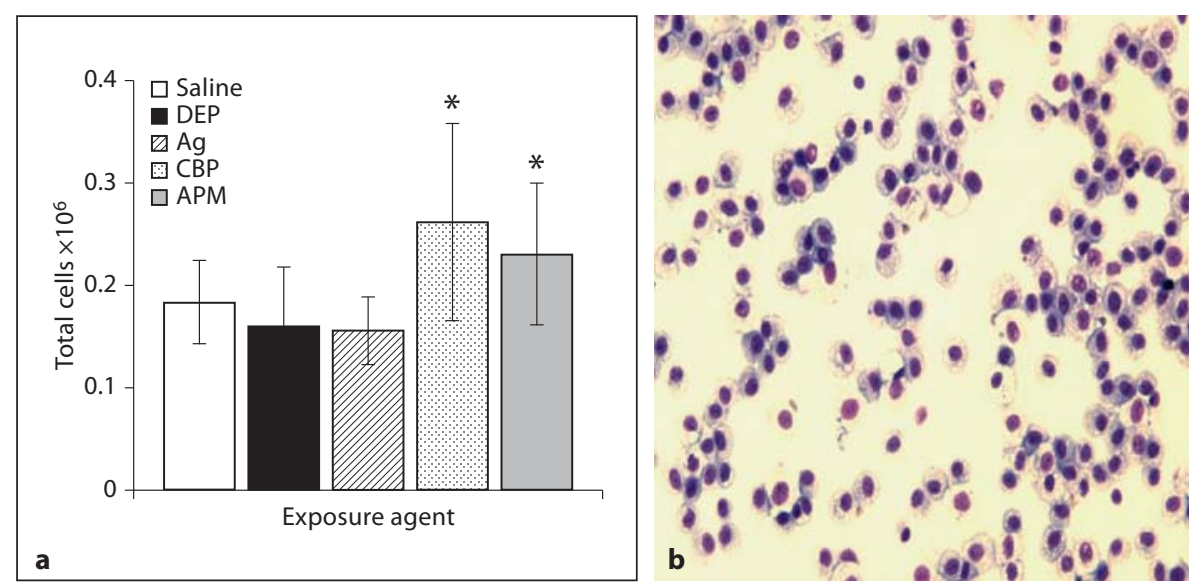

dard Bioplex cytokine assays (Bio-Rad Laboratories, Inc., USA). Data were recorded as picograms cytokine $/ 10^{6}$ cells.

\section{Statistical Analysis}

Data are expressed as mean \pm 1 SD or SEM. We set up $n=4$ independent experiments of 20 mice per experiment 1 week apart which were completed as described. Comparisons between data were tested by analysis of variance (ANOVA) and post hoc correction by Tukey's t test method (Sigma-Stat software SPSS Science, Chicago, Ill., USA) or Student's t test by Microsoft Excel Data and Statistical Analysis tool. Data were appropriately $\log _{10}$-transformed if residuals analysis suggested deviations from normal distribution with equal variance. Data were considered statistically significant with an $\alpha$ value of at least $\mathrm{p}<0.05$.

\section{Results}

\section{Changes in Inflammatory Cellular and Biochemical}

Parameters in BALF

We observed that the viability of the cells present in the BALF of all treatment groups was above $92 \%$. Additionally, the mean total number of cells was similar in mice exposed to saline, DEP or AgP while we observed greater numbers of cells from mice exposed to either CBP or APM (fig. 2a, p < 0.05). In resting mice, the major cell type observed was macrophages with few or no lymphocytes. Eosinophils were not seen in resting mice, and the presence of neutrophils was very rare (fig. $2 b, 3 a, b)$.

We also evaluated the inflammatory response by differential enumeration of cells on acute exposure to PM (fig. 3a, b). The most prominent cell type observed was the macrophage and the numbers observed differed markedly between groups. Acute aspiration of CBP or APM induced greater neutrophil infiltration as compared to saline exposure in mice $(\mathrm{p}<0.05)$ or other par- ticles including DEP (fig. 3a, b). We also saw enhanced lymphocyte recruitment but only in mice exposed to $\mathrm{AgP}$ (fig. 3a, b, c, p > 0.05).

By contrast, eosinophilic infiltration was only seen on acute instillation of APM (fig. 3a, b, p < 0.05). We also noted a variable presence of internalized PM residue in macrophages depending on the treatment (fig. 3b). The microscopic images of stained cytospinned BALF cells showed that CBP residue was present in macrophages and to a lesser extent they were seen for APM, AgP and DEP in BALF macrophages. These studies confirmed deposition of PM in the lower airways and their uptake by cells found in the BALF of the lower airways.

We also measured biochemical endpoints indicative of cytotoxicity and cellular activation (fig. 4). In this context, $24 \mathrm{~h}$ following aspiration of PM species, we measured total protein content (a marker of epithelial damage), LDH activity (a marker of gross cellular damage) and $\beta$-glucuronidase activity (a surrogate marker of macrophage activation) of the BALF (fig. 4). We found epithelial damage on exposure to engineered AgP (fig. 4, p $<$ $0.05)$, while no changes were found in any of the APMexposed mice. Enhanced LDH release was also only seen in AgP-exposed mice (fig. $4, \mathrm{p}<0.05$ ). By contrast, CBP, APM and AgP augmented $\beta$-glucuronidase activity (macrophage activation) in BALF as compared with mice exposed to saline alone (fig. $4, \mathrm{p}<0.05$ ). We found DEP to be the least active PM species in measures of epithelial barrier integrity, cytotoxicity or macrophage activation.

\section{Assay of Peripheral Bronchial Lymph Node Cell Activation}

We confirmed that oropharyngeal instillation deposited PM to the lower conducting airways and lung (fig. 5a). 

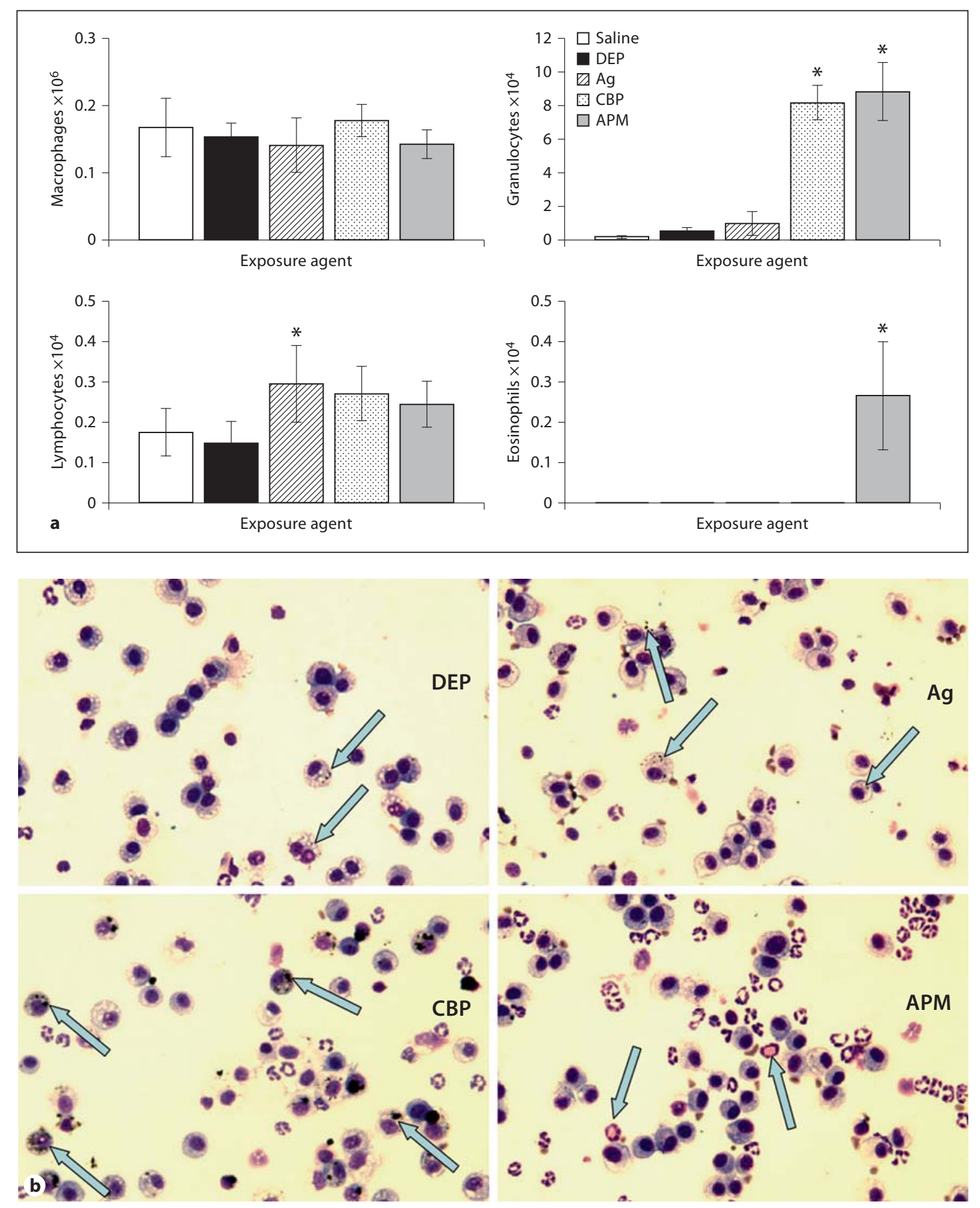

Fig. 3. Detailed quantitation of differential cell frequencies found in the BALF of PM-exposed mice. Inflammatory cell infiltration was determined on cytocentrifuged cell preparations (see 'Materials and Methods') in BALF $24 \mathrm{~h}$ following PM exposure (a). Shown here are the arithmetic mean counts \pm SD of $n=16-19$ total mice per exposure, for lymphocytes, macrophages, granulocytic neutrophils and eosinophils. Eosinophilic infiltration was only seen in APM-exposed mice. Granulocytic neutrophil infiltration was seen in both CBP- and APM-exposed mice. Signifi- cantly different from saline control: ${ }^{*} p<0.05$. Representative light microscopic images of a typical field of view of cytocentrifuged BALF preparations for each of the four exposures are also shown (b). The phagocytic ability of macrophages can be appreciated for CBP-, DEP- and AgP-exposed mice (arrows). Eosinophilic infiltration was only seen in APM-exposed mice (arrows pointing at identified eosinophils). Representative microscope images were taken from Diff Quick-stained cytospinned BALF cells from particulate exposed mice. Original magnification, $\times 100$. 


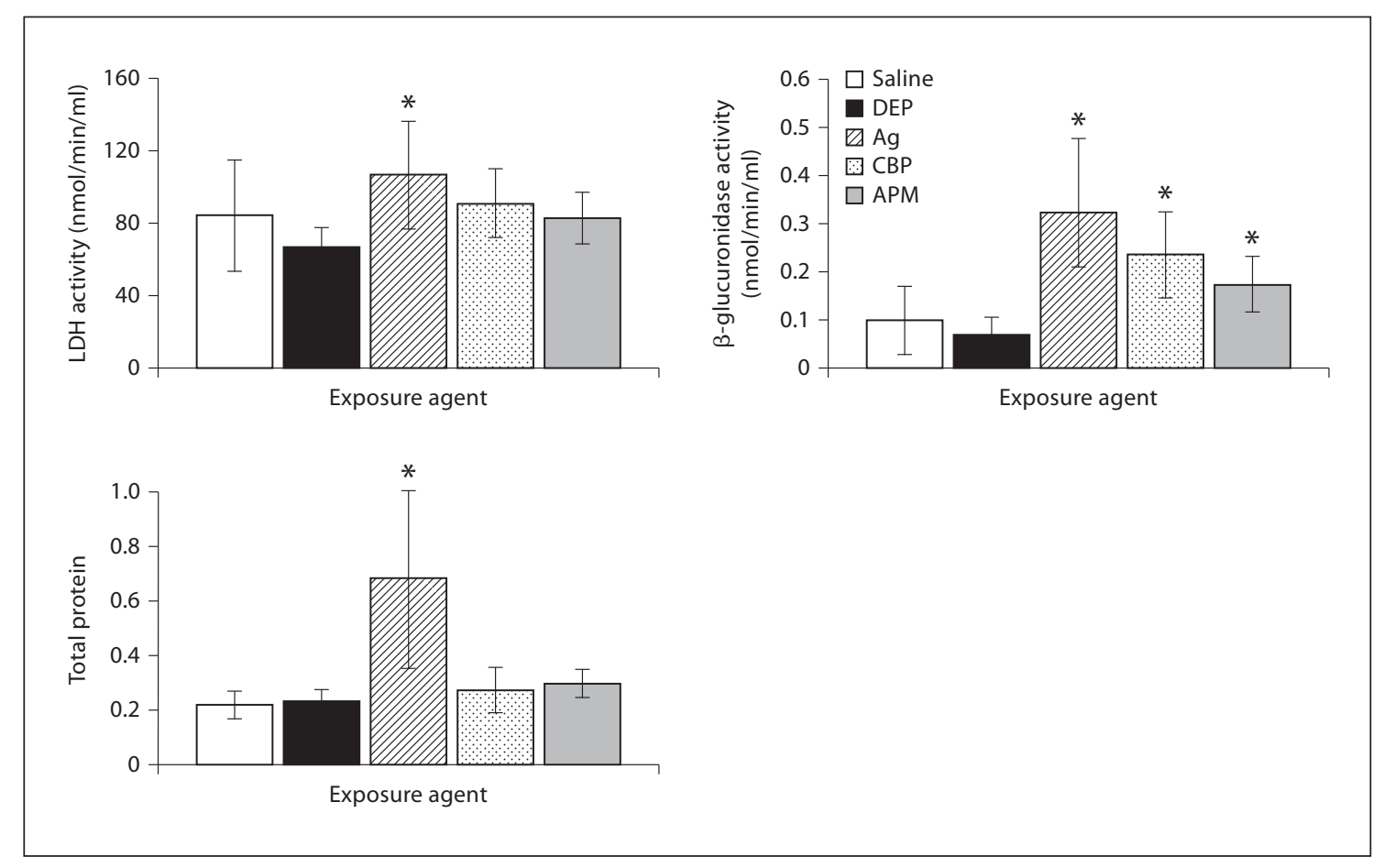

Fig. 4. Quantitation of biochemical parameters of BALF indicative of cellular cytotoxicity and activation. Increased cell permeability (tissue or cell damage), as measured by LDH release and total protein, was only seen in AgP-exposed mice. In addition, macrophage activation was measured by $\beta$-glucuronidase activity assay. By this assay, AgP, CBP and APM all differentially activated macrophages. Data are shown as the arithmetic mean of 16-19 measurements \pm SD. Measured values significantly different from saline control: ${ }^{*} \mathrm{p}<0.05$.

For example, instillation of DEP produced black/gray residues that were clearly visible in whole lung dissected from exposed mice as compared with mice that were instilled with sterile saline alone (fig. 5a). We also noted that DEP residues could be found in the draining peribronchial lymph nodes that were also enlarged as compared with nonexposed mice (fig. 5a). We suspect that the discoloration of the lymph nodes may represent PM residue that had translocated from the lung since it was not observed in non-PM-exposed mice. Such PM residues may traffic to lymph nodes in the afferent lymph and/or migrating antigen-presenting cells like DC serving as depots of PM accumulation to the draining lymph nodes.

We were also interested in establishing whether T cells in the peribronchial lymph nodes were activated on exposure to PM species (fig. 5b-d). We did this by stimulating pLNC suspensions with/without ConA to enable assessment of the repertoire of cytokines induced in mice exposed to PM, including the Th2-associated cytokines IL-4 (fig. 5b) or IL-5 (fig. 5c) and the Th1-associated cytokine IFN- $\gamma$ (fig. 5d). While ConA promoted modest
IL-4 secretion by pLNCs of mice exposed to saline, AgP or CBP (fig. 5b, $\mathrm{p}<0.01$ ), both DEP- $(\mathrm{p}<0.01)$, and APMexposed $(\mathrm{p}<0.001)$ mice secreted the greatest levels of IL-4 (fig. 5b). Also, pLNCs from APM-exposed mice secreted more IL-4 than did mice exposed to AgP or CBP (fig. 5b, p < 0.05). Concordantly, we found similar trends for IL-5 secretion by ConA-stimulated pLNCs where both DEP- $(\mathrm{p}<0.01)$ and particularly APM-exposed $(\mathrm{p}<0.001)$ mice produced the greatest IL-5 levels (fig. $5 \mathrm{c}$ ). The enhanced production of both IL- 4 and IL-5 is consistent with a Th2 proallergic immune response. By contrast, IFN- $\gamma$ secretion is indicative of a Th1-mediated immune response. While ConA promoted the greatest levels of IFN- $\gamma$ secretion from saline-exposed mice, exposure of mice to environmental or engineered PM dampened IFN- $\gamma$ secretion by pLNCs (fig. 5c). Concordant with an atopic or mixed Th1/Th2 pattern of cytokine secretion seen in asthma APM exposure promoted greater levels of IFN- $\gamma$ production as compared with $\mathrm{DEP}, \mathrm{AgP}$ or $\mathrm{CBP}$ on stimulation of pLNCs with ConA ( $p<0.05$, fig. $5 c)$. 


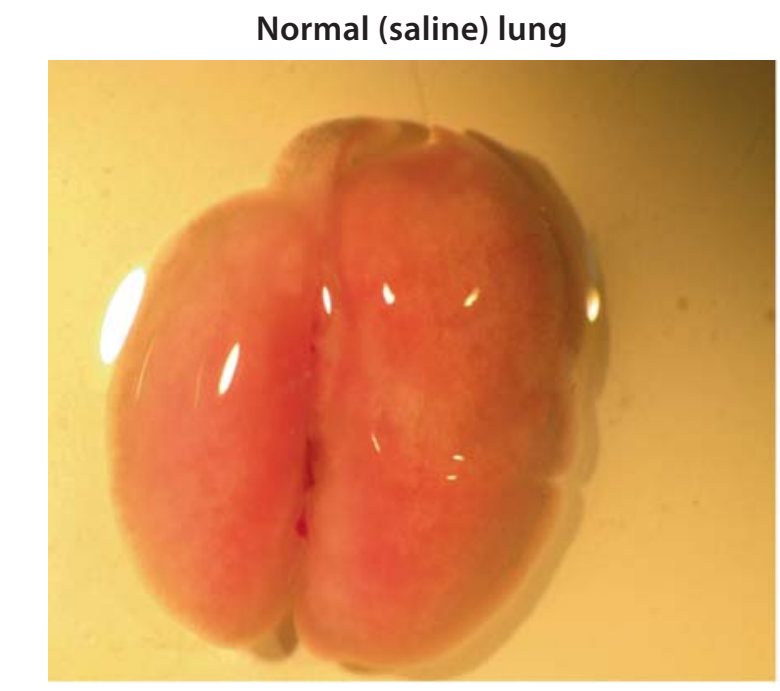

DEP-exposed lung

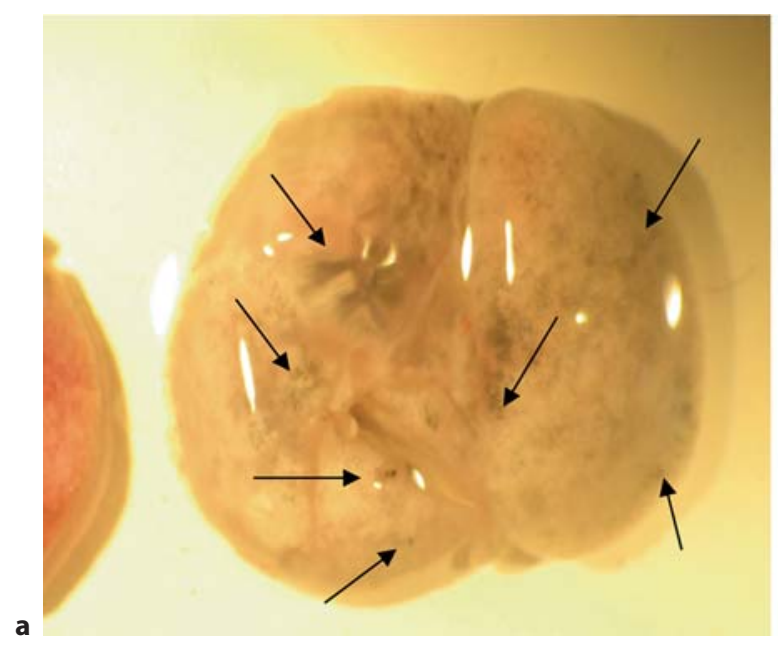

Normal pulmonary LN

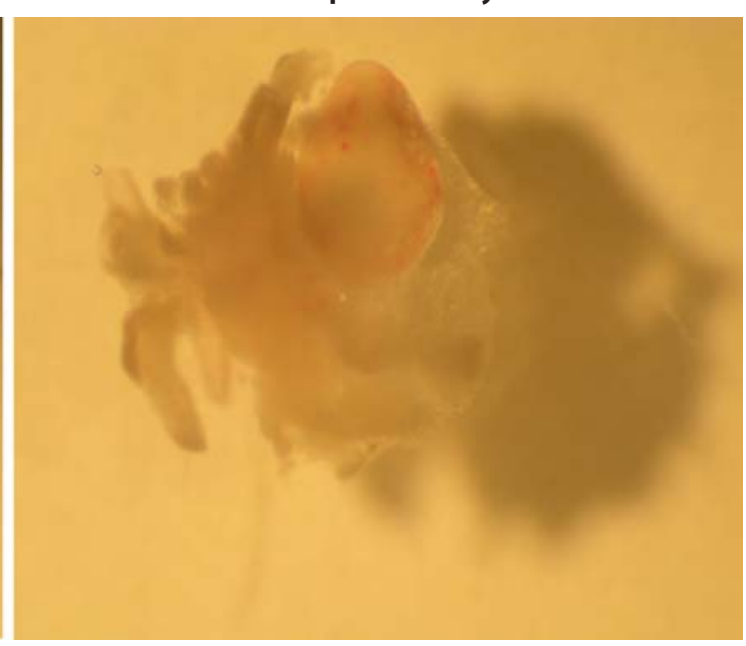

DEP residues in pulmonary $L N$

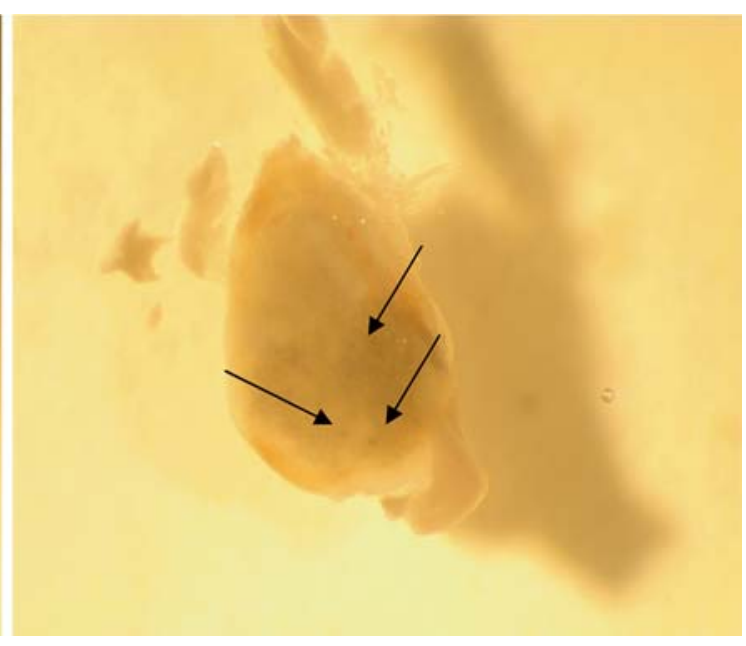

Fig. 5. Differential Th2-type immune responses of lymph node T cells following in vivo exposure to PM species. We first confirmed that oropharyngeal delivery of PM was present in the lung and in the draining peribronchial lymph nodes (a). Shown are DEP-exposed mouse lung and lymph nodes as compared with mice exposed to saline alone. Original magnification, $\times 10$. Arrows point at $\mathrm{PM}$ residues in the lungs and peribronchial lymph nodes indicating that PM translocates from the lung to the lymph nodes in migratory cells and/or the afferent lymphatics (a).

Quantitative Analysis of Primary Lung Dendritic Cell Activation ex vivo

Lung DC purification was confirmed by flow cytometric analysis of conventional $\mathrm{mDC}$ expressing very high levels of the $\beta_{2}$-integrin CD11c and analysis of pDC expressing very high levels of PDCA-1 (fig. 6a). We purified CD11c+ mDC to $>92 \%$ pure as quantified by flow cytometric analysis and PDCA-1+ DC $>93 \%$ pure (fig. 6 a). While none of the PM species altered the expression of CD11c, acute exposure of mice to either APM (MFI of
962) or AgP (MFI of 558.6) enhanced expression of PDCA-1 as compared with saline (MFI of 133.4) or DEP (MFI of 155.6) alone (fig. 6a). Upregulation of PDCA-1 on activation is thought to provoke a type I IFN secretory response and may function to regulate trafficking of secreted cytokines [40].

Function-associated markers relevant to the interaction of DC with helper CD4+ T cells were also studied ex vivo and included expression of the costimulatory molecules CD54 (ICAM-1), CD40, CD80 (B7-1) and CD86 

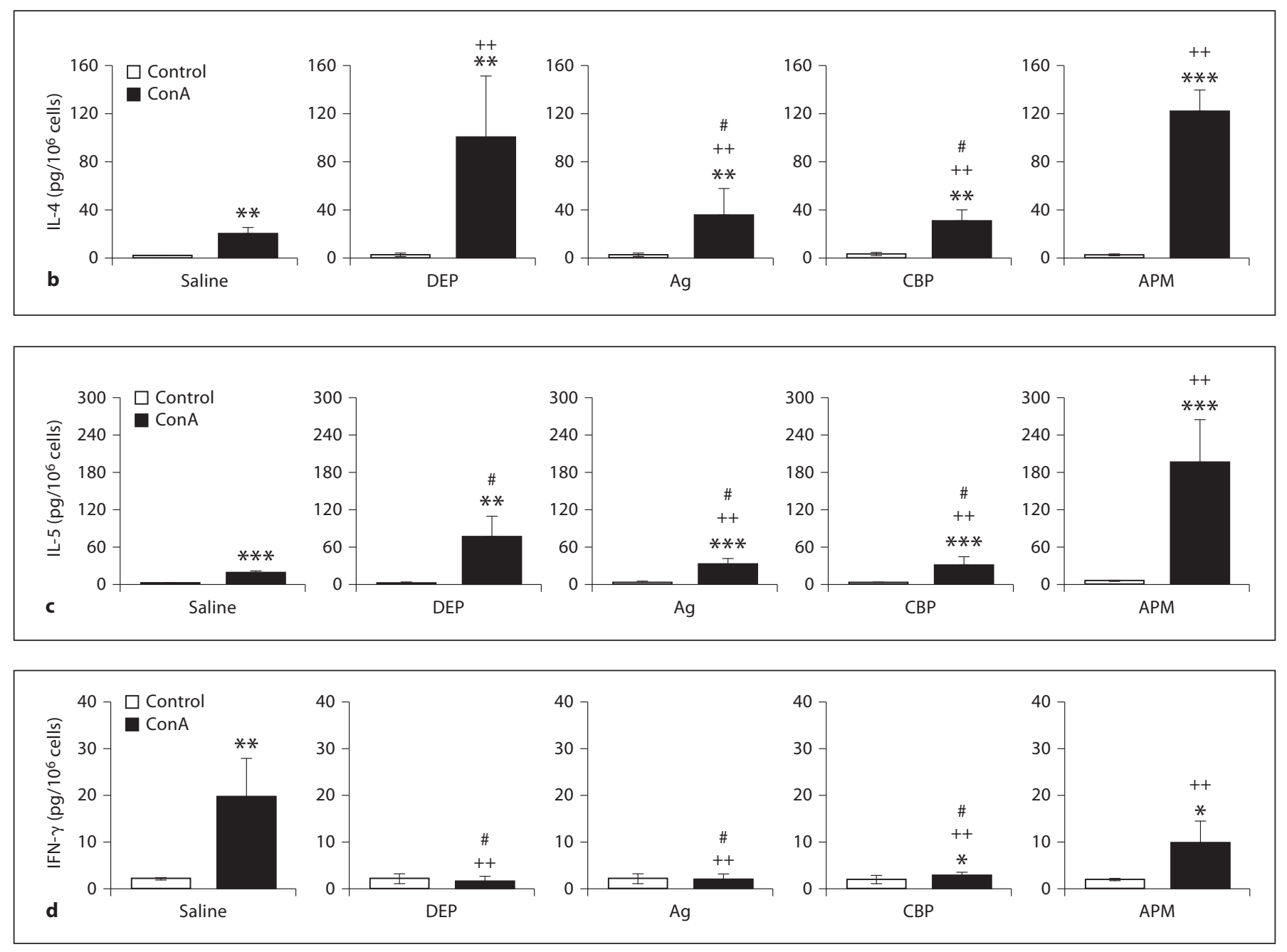

Fig. 5. Secretion of the Th2-type cytokines IL-4 (b) and IL-5 (c) and the Th1-type cytokine IFN- $\gamma$ (d) is also shown for pLNC suspensions of PM-exposed mice (see 'Materials and Methods'). Data are recorded as picograms of cytokine per $10^{6}$ cells (mean \pm SEM, $n=4 ;{ }^{* *} \mathrm{p}<0.01$ as compared with resting cells; ${ }^{++} \mathrm{p}<0.01$ as compared with saline-exposed mice; ${ }^{\#} \mathrm{p}<0.05$ as compared with DEP- or APM-exposed mice).

(B7.2) (fig. 6b). Cell-surface expression of MHC class II (Ia/Ie) was found not only to be similar between $\mathrm{mDC}$ and $\mathrm{pDC}$ subsets but remained unaltered on exposure to any of the PM species (not shown). Only APM enhanced CD54 expression by $\mathrm{mDC}(\mathrm{p}<0.05$, fig. $6 \mathrm{~b})$, while all particles differentially increased CD54 expression by pDC $(\mathrm{p}<0.05$, fig. $6 \mathrm{~b})$. This suggested that $\mathrm{pDC}$ displayed greater sensitivity to $\mathrm{PM}$ exposure than $\mathrm{mDC}$ in our model. While PM exposure did not alter CD40 expression by $\mathrm{mDC}$, minimal increases in CD40 expression by $\mathrm{pDC}$ were only seen on exposure to APM $(\mathrm{p}<0.05$, fig. 6b). While none of the particles altered CD80 expression by $\mathrm{mDC}$, all particles (with the exception of $\mathrm{CBP}$ ) enhanced CD80 expression by pDC ( $p<0.05$, fig. $6 \mathrm{~b})$, while only APM enhanced CD86 expression by both $\mathrm{mDC}$ and $\mathrm{pDC}(\mathrm{p}<0.05$, fig. $6 \mathrm{~b})$.

\section{PM-Exposed Lung Conventional mDC Potently \\ Stimulate CD4+ T Cell Activation}

One of the hallmarks that distinguish DC from other antigen-presenting cells is their potent ability to stimulate naïve helper $\mathrm{CD} 4+$ helper $\mathrm{T}$ cell (Th) activation. We compared the immune stimulation of OT.II CD4+ T cells by OVA-pulsed conventional lung $\mathrm{mDC}$ as compared with their lung pDC counterparts. We measured CD4+ $\mathrm{T}$ cell proliferation (fig. 7a) as well as the repertoire of se- 
Fig. 6. Expression of function-associated cell surface molecules by pulmonary DC subsets. Highly purified PDCA-1+ pDC and $\mathrm{CD} 11 \mathrm{c}+$ conventional $\mathrm{mDC}$ were obtained from the pooled lungs of 4 mice for each individual experiment. Typical flow histograms (a) of purified pDC and mDC show percent positively stained cells and MFI units for saline-, APM-, DEP- and AgP-exposed mice. Similar data were also found for CBP (not shown).

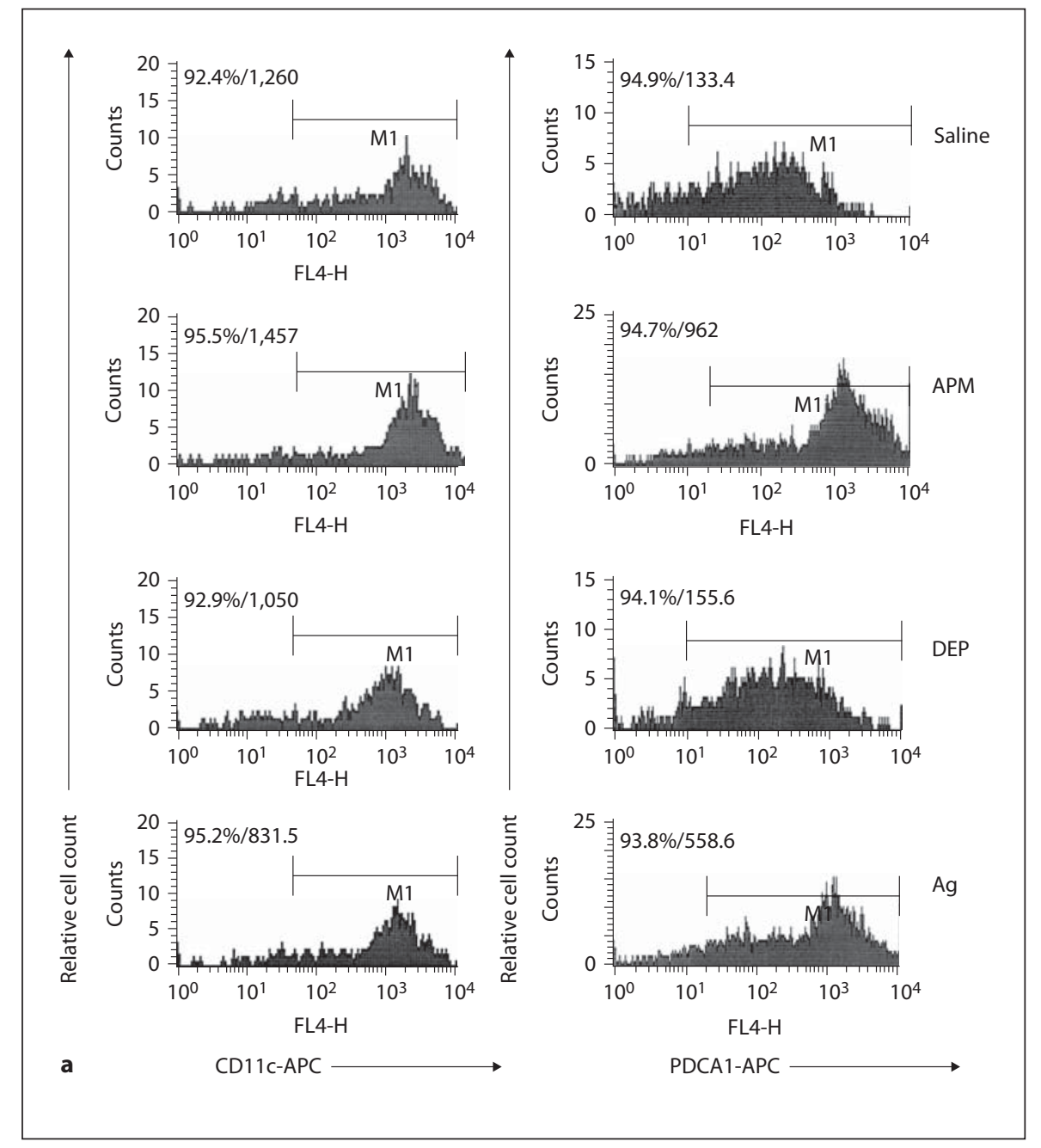

creted cytokines by the DC-T cell coculture indicative of a Th1 or a 'proallergic' Th2-type immune response (fig. 7b-d). We also measured immunomodulatory cytokine production in DC-T cell cocultures (data not shown). We found that at rest and following exposure to all PM species, OVA-pulsed conventional $\mathrm{mDC}$ were comparably more potent than pDC in driving CD4+ T cell proliferation with the greatest stimulation provoked by $\mathrm{AgP}$ $(p=0.043)$ or APM exposure $(p=0.039$, fig. $7 a)$.

We also studied cytokine secretion that indicated whether a pro-Th1 (IFN- $\gamma$, fig. $7 \mathrm{~b}$ ) or pro-Th2/proallergic (IL-5 and IL-13, fig. 7c, d) response was evident in our cocultures. Conventional mDC stimulated greater IFN- $\gamma$ secretion as compared to their pDC counterparts ( $\mathrm{p}<$ 0.01 , fig. $7 \mathrm{~b}$ ) in mice that were exposed to all PM species and as compared with mice exposed to saline alone ( $\mathrm{p}<$ 0.01 , fig. $7 b$ ). The greatest levels of IFN- $\gamma$ secretion were seen in cocultures stimulated by $\mathrm{mDC}$ exposed to $\mathrm{AgP}$ in vivo as compared with $\mathrm{mDC}$ exposed to CBP $(\mathrm{p}=0.047)$, $\operatorname{DEP}(\mathrm{p}=0.0044)$ or APM $(\mathrm{p}=0.042$, fig. $7 \mathrm{~b})$. By contrast, only DEP-exposed pDC instructed augmented levels of IFN- $\gamma$ as compared with saline-exposed $\mathrm{pDC}(\mathrm{p}=0.051)$. We also measured secretion of the Th2-associated cytokines IL-5 and IL-13. Under conditions of AgP, CBP or APM (and even under resting/saline exposure conditions), $\mathrm{mDC}$ stimulated the highest levels of IL-5 secretion as compared with pDC (fig. 7c). We also found a trend towards higher levels of IL-5 secretion in APM-exposed $\mathrm{mDC}$ as compared with $\mathrm{mDC}$ exposed to CBP $(\mathrm{p}=0.085)$, $\operatorname{DEP}(\mathrm{p}=0.053)$ or $\operatorname{AgP}(\mathrm{p}=0.083)$. We observed a similar pattern of IL-13 secretion by CD4+ T cells stimulated by PM-exposed $\mathrm{mDC}$ (fig. 7d). First, $\mathrm{mDC}$ stimulated greater levels of IL-13 secretion than their pDC counterparts ( $p<0.05$, fig. $7 d$ ). Second, concordant with our observa- 


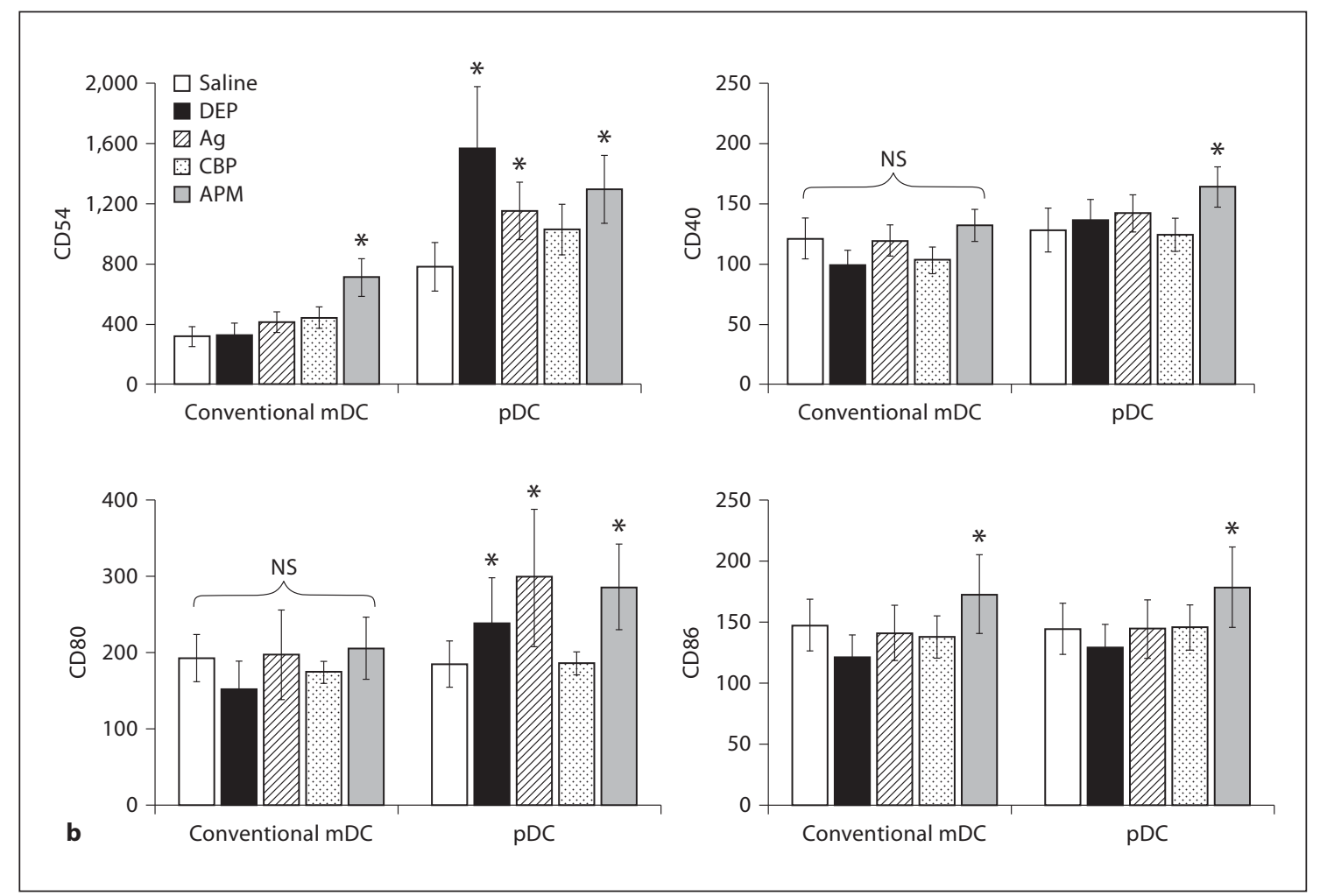

Fig. 6. Expression of function-associated cell surface molecules by pulmonary DC subsets. Highly purified PDCA-1+ pDC and CD11c+ conventional $\mathrm{mDC}$ were obtained from the pooled lungs of 4 mice for each individual experiment. The cell-surface expression of the costimulatory molecules CD54, CD40, CD80 and CD86 whose expression is described as geometric MFI units is shown (b, mean $\pm \mathrm{SD}, \mathrm{n}=4 ;{ }^{*} \mathrm{p}<0.05$ of exposed mice as compared with saline-only control groups). NS = Nonsignificant differences between PM-exposed and saline only-exposed animals.

tions for IL-5 secretion above, there was a trend towards higher levels of IL-13 secretion in CD4+ T cells stimulated by APM-exposed $\mathrm{mDC}$ as compared to CBP- $(\mathrm{p}=0.013)$, DEP- $(\mathrm{p}=0.074)$ or AgP-exposed $(\mathrm{p}=0.016) \mathrm{mDC}$. We also found that $\mathrm{pDC}$ exposed to APM $(\mathrm{p}<0.005)$ or DEP $(p<0.056)$ stimulated greater levels of IL-13 secretion in coculture with CD4+ T cells than pDC that were exposed to saline, $\mathrm{AgP}$ or CBP (fig. 7d). This is consistent with the hypothesis that exposure to environmental DEP or APM may drive a proallergic immune response in vivo.

Finally, we also measured immunomodulatory cytokines thought to play important roles in promoting proallergic immune responsiveness or immune-dampening functions in host immunity (data not shown). First, we measured IL-6 secretion and found that lung mDC stimulated greater levels of this cytokine than did pDC ( $\mathrm{p}<$ 0.03 , not shown). APM-exposed $\mathrm{mDC}$ also encouraged the greatest levels of IL- 6 secretion in coculture with
$\mathrm{CD} 4+\mathrm{T}$ cells as compared with all other PM species $(\mathrm{p}<$ $0.05)$. While stimulated $\mathrm{mDC}$ secreted far greater levels of tumor necrosis factor- $\alpha$, IL-10 and IL-12p40 than their pDC counterparts, we found that APM-exposed mDC secreted the lowest levels of IL-10 as compared with $\mathrm{mDC}$ exposed to DEP, AgP or CBP ( $\mathrm{p}<0.01$, not shown). Release of IL-10 serves important roles in the immunomodulation of Th1 and Th2 immune responses as well as suppression of antigen presentation by cells such as DCs. It is also hypothesized that IL-10 plays an important role in stimulating B cell maturation and antibody production.

\section{Discussion}

The objective of this research was to expand on our comprehensive in vitro studies of the immunological and inflammatory effects of PM exposure in allergic innate 

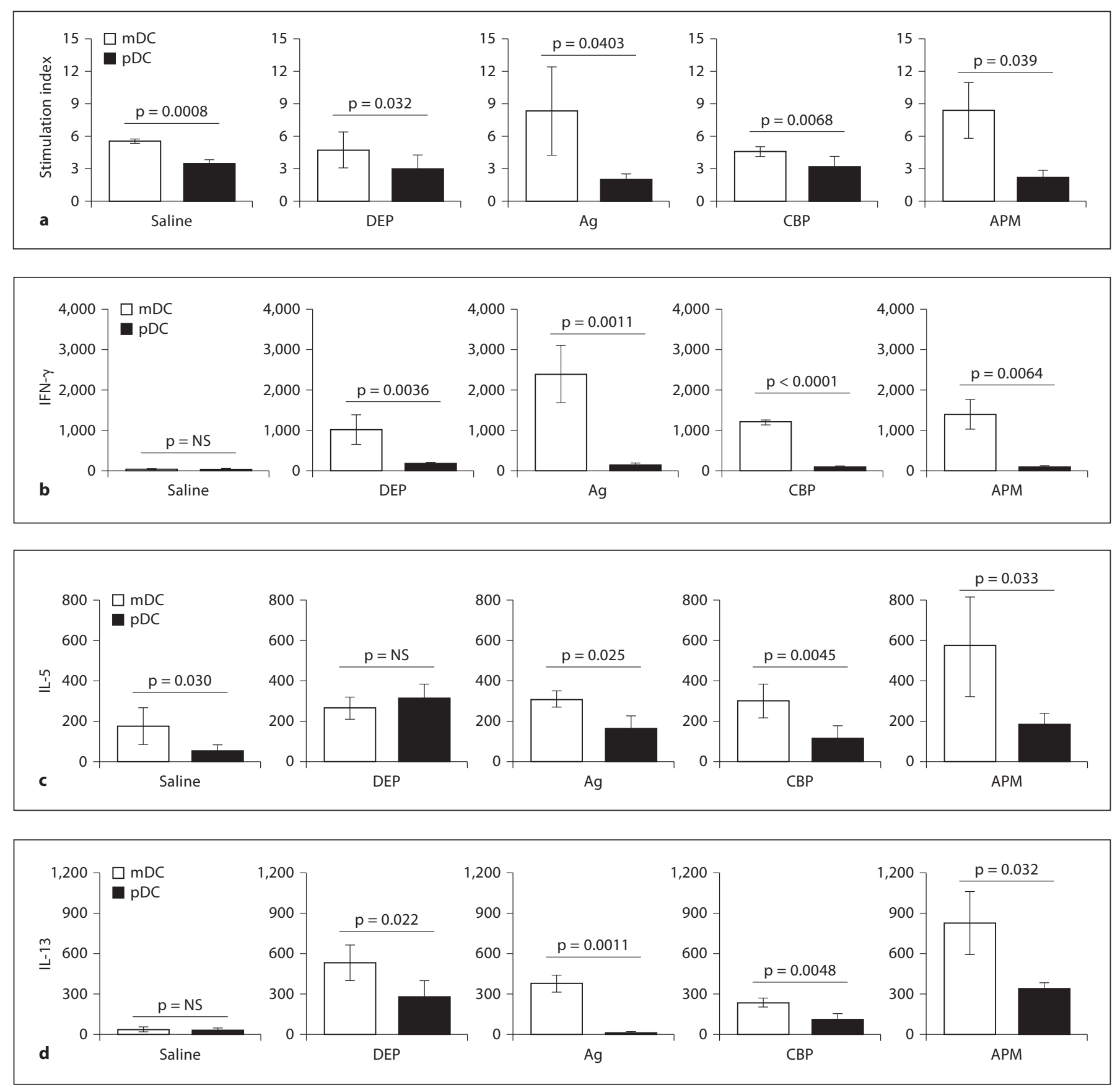

Fig. 7. Stimulation of naïve CD4+ T cell proliferation and Th1/ Th2 cytokine elaboration by in vivo PM-exposed lung DCs. Purified DC of PM-exposed mice were pulsed with OVA $(50 \mu \mathrm{g} / \mathrm{ml}$, $4 \mathrm{~h}$ ) as a model antigen, washed and cocultured with highly purified naïve CD4+ CD62L+ T cells of transgenic OT-II.2 mice expressing the $\mathrm{T}$ cell receptor specific for $\mathrm{OVA}_{323-339}$ and MHC class II-A ${ }^{b}$ (for a ratio of DC to T cells of 1:5), as described above. T cell proliferation was measured based on a standard BrdU uptake assay (a). Data are presented as the mean stimulation index of at least 4 individual experiments $\pm \mathrm{SD}$, where: stimulation index $=$
[(OD coculture) - (OD T cells cultured alone)]/(OD T cells cultured alone). In each individual experiment DCs were isolated from the pooled lungs of 4 animals. The indicated $\mathrm{p}$ values show that $\mathrm{mDC}$ were more effective than their $\mathrm{pDC}$ counterparts with the greatest levels of proliferation seen in Ag- and APM-exposed mice (a). Coculture supernatants were assayed by multiplex cytokine arrays for secretion of the Th1-associated cytokine IFN- $\gamma(\mathbf{b})$ and the Th2-associated cytokines IL-5 (c) and IL-13 (d). Data were recorded as picograms of cytokine per $10^{6}$ cells. 
immunity by exploring the acute effects of engineered, environmental emission-source diesel PM and ambient PM instillation on pulmonary inflammation, particle uptake and immune activation of DC subsets in vivo. Thus we wished to establish the early or acute effects of PM exposure in vivo and relate this to the notion that these agents may behave as immune adjuvants in vivo. Studying DC in pulmonary immune responses to environmental PM exposure stems from our knowledge that DC are uniquely positioned through peripheral tissues such as the lung and lymphoid or nonlymphoid organs where they are specialized for the rapid uptake, endogenous processing and presentation of antigens to naïve CD4+ and CD8+ T cells. There is a paucity of data describing interactive effects as well as mechanisms affected on activation of DC by respirable pollutants.

Our data suggest that PM species, and particularly APM and DEP, did not behave as conventional adjuvants since they were immunostimulatory both in vitro $[5,6$, $12,19]$ and in vivo as detailed in this study. Since these environmental PM species are complex agents, it is likely that they serve as a priming and secondary stimulus in their own right by presenting to the immune system several ligands that are recognized by the innate immune system as 'danger signals'. We have previously demonstrated a noncanonical and pro-inflammatory pathway of DC activation on exposure to PM and aeroallergens such as ragweed extract in vitro $[5,6,12,18,19]$. It is hypothesized by many groups as well as work of our own that APM or DEP exhibits immune adjuvant properties $[5,6,12,18,19,28,33,39,41]$. However, virtually nothing is known of the early acute inflammatory effects of PM exposure in naïve mouse models in vivo.

In the current work, we have extended our prior in vitro studies $[5,6,12,19]$ by exploring the in vivo effects of PM in a naïve mouse model of acute APM exposure. It remains unclear whether DCs are activated by acute exposure to PM or by other factors. Suggested factors contributing to DC activation include damage to the lung epithelium and oxidative stress responses [42, 43]. There is in vitro evidence suggesting that CBP directly induce DC maturation [30]. Direct in vitro exposure of human and mouse DC to environmental stimuli such as APM and $\mathrm{DEP}$ also promoted $\mathrm{mDC}$ activation and a dysregulated pattern of cytokine responses from naïve CD4+ T cells $[5,6,19]$ and stimulated a pro-oxidative mode of primary lung DC maturation [12]. We confirmed that both environmental APM and DEP were potent stimulators of $\mathrm{mDC}$ and $\mathrm{pDC}$ as well as proallergic immune responsiveness. By modeling the exposure of mice to APM, emission-source DEP and engineered PM species (e.g. $\mathrm{AgP}$ and $\mathrm{CBP}$ ), we have integrated the cellular and molecular effects of all the bioorganic and inorganic components that constitute ambient PM. This approach crucially accounts for possible cooperative or antagonistic interactions in the experimental model.

We first assessed ways by which environmental as well as engineered PM induces lung tissue damage and activation of various innate inflammatory cells. First, evidence of lung inflammation was observed in the BALF following aspiration of both CBP and APM as defined by greater neutrophil recruitment to the lung as compared to the saline control as well as the laboratory-generated AgP and environmental DEP. While macrophage numbers in BALF remained consistent between treatments, only on acute exposure of mice to APM did we see infiltrating eosinophils. The infiltration of eosinophils to the lung just $24 \mathrm{~h}$ after acute exposure to only APM could be important since under normal resting conditions, eosinophils should be absent from the lung. IL-5 is known to be a key mediator in eosinophil activation, survival and recruitment $[44,45]$. This observation of eosinophil accumulation in the lung is consistent with the ability of APM to drive enhanced secretion of IL-5 in ConA expanded primary peribronchial lymph node cultures (fig. 5c) and in cocultures of naïve CD4+ T cells stimulated by APMexposed primary lung $\mathrm{mDC}$ (fig. 7c). IL-5 plays an important role in eosinophil activation which may also serve as producers of this cytokine [46]. It is likely that the ability of PM exposure to provoke IL-5 secretion is in part responsible for the mobilization and accumulation of eosinophils in the lung, as we reported here.

We also found that, in contrast to other exposures, IL- 5 secretion by DEP-exposed $\mathrm{mDC}$ and $\mathrm{pDC}$ was very similar and the reasons for this are unclear (fig. 7c). No increases in the Th2-type cytokines were observed following CBP exposure. Remarkably, the observed Th2type immune activation of allogeneic CD4+ T cells induced by DEP- and APM-exposed mDCs was not associated with epithelial barrier integrity or even, in the case of DEP, with general lung inflammatory responses in our model. We do not suspect that the observed eosinophilic infiltration was associated with perturbed epithelial barrier integrity as measured by LDH release into the BALF. Marked increases in the extent of epithelial damage were only observed following engineered AgP exposure, conditions that also provoked the greatest levels of cellular damage as defined by LDH release and total protein detected in BALF. We also found that AgP, CBP and APM differentially induced activation of lung macrophages as 
determined by increased $\beta$-glucuronidase activity in the BALF (fig. 4).

A known route of PM clearance from the lung involves endocytic and phagocytic mechanisms by macrophages $[15,16,35,47]$. Thus PM uptake by macrophages or presumably DC may lead to their activation and subsequent release of $\beta$-glucuronidase in the lung. We also observed semiquantitative differences between the type of $\mathrm{PM}$ exposure and the relative frequency of macrophages that were seen to have obvious particle residues present in their cytoplasm (fig. 3b). We concluded that $24 \mathrm{~h}$ following either DEP or APM exposure, there were very few macrophages containing any particle residue in BALF macrophages.

In addition, our analyses of purified $\mathrm{mDC}$ indicated that only on exposure to APM was enhanced expression of the costimulatory cell-surface receptors CD54 (ICAM1) and CD86 observed. Augmentation in the expression of costimulatory molecules of DC provides an important signal in consolidating the interaction of DC with naïve $\mathrm{T}$ cells that promotes both $\mathrm{T}$ cell proliferation and polarization of a Th1- or Th2-associated immune response. Subtle differences in DC maturation, associated with different patterns of expression of costimulatory molecules (such as CD80 and CD86), can influence the outcome of an immune response $[23,40]$. Thus it was interesting to observe that while exposure of mice to APM augmented expression of only CD54 and CD86 by mDC, the expression by $\mathrm{pDC}$ of all costimulatory molecules was increased.

Stimulation of alloreactive CD4+ T cells is an important indication of an activated DC. We found that particulate-exposed mDCs stimulated $\mathrm{CD} 4+\mathrm{T}$ cells more effectively than pDCs. A marked difference between the ability of lung $\mathrm{mDC}$ and $\mathrm{pDC}$ to promote $\mathrm{T}$ cell proliferation was seen in mice exposed to either AgP or PM as measured by BrdU incorporation in CD4+ T cells. The increases in cytokine production in the cocultures were also mainly restricted to the dominance of $\mathrm{mDC}$ activation. On coculture of $\mathrm{mDC}$ from $\mathrm{AgP}$-exposed mice with $\mathrm{CD} 4+\mathrm{T}$ cells, we observed profound increases in IL$12 \mathrm{p} 40$, IL-10 and IFN- $\gamma$ production. The enhanced levels of IL-10 may explain in part the dampened neutrophilic influx in the lungs of AgP-exposed mice.

The mDC/allogeneic CD4+ T cell cocultures showed that in vivo exposure to environmental cues like DEP and APM induces $\mathrm{mDC}$ activation and a Th2-skewed pattern of cytokine responsiveness. This latter observation supports the hypothesis that certain PM species induce sensitization by $\mathrm{mDC}$ activation $[30,33]$. Moreover, exposure

Activation of Lung Dendritic Cells by

Particulate Matter in vivo of mouse models to 'real-world' environmental PM such as DEP and APM impart major influences on the innate and adaptive immune response. The immunostimulatory effects of 'unpurified or unfractionated' $P M$, as shown in this study, were shown at the levels of activated DC and pro-Th2 biased outcomes from ConA-stimulated primary lymph node cultures and allogeneic stimulatory cocultures of PM-exposed DC and naïve CD4+ T cells.

Also, others have shown and discussed in detail the emerging concept that immunostimulatory 'real-world' exposure such as to PM or aeroallergens does not necessarily drive host-protective Th1-biased responses as conventionally considered [48]. By contrast, it is likely that such respirable immunostimulatory agonists that constitute 'ambient real-world' environments, may exert a greater potential to drive Th2 (or even tolerogenic) polarized immune responses $[49,50]$ than was previously considered. It is likely that transient and repeated episodic exposure to ambient PM or environmental DEP possesses the intrinsic potential to not only provide acute Th2mediated inflammatory and mucosal immune responses but the potential to sustain Th2-mediated hypersensitivity to common allergens including ragweed, house dust mite allergen or other seasonal allergens [48].

Further, several lines of evidence have proposed that bronchial epithelial cells are targeted by respirable pollutants in much the same way as the abundant DC that interdigitate those epithelial cells and 'survey' the external environment [51-53]. It has been shown that ambient PM also induces epithelial cells to produce amphiregulin, granulocyte-macrophage colony-stimulating factor and MIP-3 $\alpha$ [53-56], that are known to induce recruitment and survival of DC. It seems likely therefore that DC will be among the first cells to sense and respond to inhaled $\mathrm{PM}$, although the importance of bronchial/pulmonary epithelial cells cannot be overlooked. It is possible that exposure to PM disrupts the integrity of pulmonary epithelial cells and thereby releases inflammatory cytokines that activate DC and drive Th2-mediated allergic immunity as suggested by others $[57,58]$. An attractive mechanism responsible for DC activation by epithelial cells suggests release of granulocyte-macrophage colony-stimulating factor and thymic stromal lymphopoietin (TSLP) on exposure to particulate pollutants that may also involve oxidative stress and the generation of reactive oxygen species in the activation of pulmonary DC $[11,42,54$, $57,59]$.

In the murine model at least, release of TSLP by bronchial/pulmonary epithelial cells may also instruct DC activation and secretion of Th2-driving cytokines by them, 
which is not surprising given the notion that TSLP conditions the lung microenvironment for Th2-mediated immune responses [60]. However, it is likely that both the perturbation of epithelial cell barrier integrity and direct activation of DC are important in the elicitation of a proallergic innate immune response to 'environmental danger signals' since interdigitating DC are after all capable of sampling ambient PM via the tight junctions of pulmonary epithelia $[35,52,61-64]$. It is also important to point out that it has been shown that relatively larger macromolecules (for example respirable coarse/fine ambient PM) may not overcome the integrity of the bronchial epithelial cell barrier and instead may be deposited and accumulated on the luminal surface of the epithelia where DC residing essentially underneath the epithelial barrier may directly capture those particles without affecting the integrity of the epithelia at all [26].

We are beginning to appreciate the potential consequences of the interaction between cells of the innate immune system and exposure to PM species in driving pulmonary inflammation and Th2-mediated proallergic diseases. Our studies exploring immunological and inflammatory effects of laboratory-generated (engineered) PM and environmental ambient PM exposure in vivo are concordant with recently described work [65]. Taken together, we have shown that exposure to APM and DEP induces in vivo $\mathrm{mDC}$ activation and their stimulation of naïve lymph node resident $\mathrm{T}$ cells and in the absence of either increased cytotoxicity or changes in lung epithelial permeability. We also reported polymorphonuclear leukocyte and eosinophilic infiltration in the lungs of APMexposed mice without any secondary allergen challenge, an observation consistent with a proallergic response.

We conclude that ambient environmental PM exposure may directly activate lung DC, thus contributing to their translocation to the lung draining lymph nodes and subsequent provocation of a Th2-biased immune response. Our work supports the concept that environmental PM species possess selective abilities to drive Th2-biased immune responses, which is one of the central tenets of allergic respiratory diseases like asthma as suggested by others and from our prior work $[3,5,6,12,15,28,48$, $65]$. We have also reported marked differences in the biological effects of the particle types studied and their differential abilities to induce Th2-biased immune responses and DC activation. Subsequent studies will be designed such that 'real-world' inhalation exposure models can be developed, testing both acute and repeated exposure. Attempts to study the relationship between host innate immunity and exposure to environmental respirable pollut- ants should enable a greater appreciation of the immune pathology of allergic diseases such as asthma and provide improved tools for the management of allergic airways disease.

\section{Acknowledgments}

The authors would like to thank Nancy Corson and Pamela Mercer for their excellent technical assistance with mouse exposure experiments and BALF chemistry measurements. This project was funded in part by NIH/NIEHS Pilot Project Grants P30 ES03819 and P30 ES001247 (both awarded to M.A.W.), The US Environmental Protection Agency (grant No. R82672401, awarded to P.B.) and the National Institute for Environmental Health Sciences (grant No. PO1 ES09606, awarded to P.B.), The University of Rochester US - EPA Particulate Matter Center (grant No. RD83241501) and The University of Rochester NIEHS Center (grant No. P30 ESO1247), The Department of Medicine, University of Rochester School of Medicine and Dentistry and the Dutch Asthma Fund (awarded to G.F.G.B. and R.H.H.P.). Please note that the research described in this article has been funded in part by the United States Environmental Protection Agency through grant agreement R82672401 awarded to Dr. Patrick Breysse and has not been subjected to the Agency's peer and policy review and thus does not necessarily reflect the views of the Agency and no official endorsement should be inferred or concluded from this work. In addition, the senior author of this work, Dr. Marc A. Williams, performed the studies and data analyses reported herein while entirely employed by the University of Rochester and School of Medicine, Rochester, N.Y., USA. Although the corresponding address of Dr. Williams is provided as The US Environmental Protection Agency, Research Triangle Park, N.C., USA, none of the work whatsoever was conducted at that Agency and thus the research data, discussion and conclusions reported in this article do not necessarily reflect the views of the Agency at all and no official endorsement should be inferred or concluded from this work.

References

1 Cohn L, Elias JA, Chupp GL: Asthma: mechanisms of disease persistence and progression. Annu Rev Immunol 2004;22:789-815.

2 Galli SJ, Tsai M, Piliponsky AM: The development of allergic inflammation. Nature 2008;454:445-454.

-3 Nel AE, Diaz-Sanchez D, Ng D, Hiura T, Saxon A: Enhancement of allergic inflammation by the interaction between diesel exhaust particles and the immune system. J Allergy Clin Immunol 2008;102:539-554.

$\checkmark 4$ Wills-Karp M: Immunologic basis of antigen-induced airway hyperresponsiveness. Annu Rev Immunol 1999;17:255-281.

5 Porter M, Karp M, Killedar S, Bauer SM, Guo J, Williams D, Breysse P, Georas SN, Williams MA: Diesel-enriched particulate matter functionally activates human dendritic cells. Am J Respir Cell Mol Biol 2007;37:706719. 
6 Williams MA, Porter M, Horton M, Guo J, Roman J, Williams D, Breysse P, Georas SN: Ambient particulate matter directs nonclassic dendritic cell activation and a mixed $\mathrm{T}(\mathrm{H}) 1 / \mathrm{T}(\mathrm{H}) 2$-like cytokine response by naive CD4(+) T cells. J Allergy Clin Immunol 2007;119:488-497.

7 Miyabara Y, Ichinose T, Takano H, Lim HB, Sagai M: Effects of diesel exhaust on allergic airway inflammation in mice. J Allergy Clin Immunol 1998;102:805-812.

8 Granum B, Løvik M: The effect of particles on allergic immune responses. Toxicol Sci 2002;65:7-17.

-9 Mamessier E, Nieves A, Vervloet D, Magnan A: Diesel exhaust particles enhance T-cell activation in severe asthmatics. Allergy 2006;61:581-588.

10 Dellinger B, Pryor WA, Cueto R, Squadrito GL, Hegde V, Deutch WA: Role of free radicals in the toxicity of airborne fine particulate matter. Chem Res Toxicol 2001;14:13711377.

-11 Baulig A, Singh S, Marchand A, Schins R, Barouki R, Garlatti M, Marano F, BaezaSquiban A: Role of Paris PM(2.5) components in the pro-inflammatory response induced in airway epithelial cells. Toxicology 2009;261:126-135.

12 Williams MA, Rangasamy T, Bauer SM, Killedar S, Karp M, Kensler TW, Yamamoto M, Breysse P, Biswal S, Georas SN: Disruption of the transcription factor Nrf2 promotes pro-oxidative dendritic cells that stimulate Th2-like immunoresponsiveness upon activation by ambient particulate matter. J Immunol 2008;181:4545-4559.

13 Kadiiska MB, Mason RP, Dreher KL, Costa DL, Ghio AJ: In vivo evidence of free radical formation in the rat lung after exposure to an emission source air pollution particle. Chem Res Toxicol 2007;10:1104-1108.

14 Becker S, Dailey LA, Soukup JM, Grambow SC, Devlin RB, Huang YC: Seasonal variations in air pollution particle-induced inflammatory mediator release and oxidative stress. Environ Health Perspect 2005;113: 1032-1038.

15 Blank F, Rothen-Rutishauser B, Gehr P: Dendritic cells and macrophages form a transepithelial network against foreign particulate antigens. Am J Respir Cell Mol Biol 2007;36:669-677.

-16 Geiser M: Morphological aspects of particle uptake by lung phagocytes. Microsc Res Tech 2002;57:512-522.

17 van Rijt LS, Lambrecht BN: Dendritic cells in asthma: a function beyond sensitization. Clin Exp Allergy 2005;35:1125-1134.

18 Rangasamy T, Williams MA, Bauer S, Trush MA, Emo J, Georas SN, Biswal S: Nrf2 inhibits the maturation of murine dendritic cells by ragweed extract. Am J Respir Cell Mol Biol 2010;43:276-285.

Activation of Lung Dendritic Cells by Particulate Matter in vivo
19 Williams MA, Cheadle C, Watkins T, Tailor A, Killedar SY, Breysse P, Barnes K, Georas SN: TLR2 and TLR4 as potential biomarkers of environmental particulate matter exposed human myeloid dendritic cells. Biomarker Insights 2007;2:225-239.

20 Hammad HM, Kool M, Lambrecht BN: Role of airway dendritic cell subsets in asthma. Cytometry B Clin Cytom 2007;72B:120-121.

-21 Lambrecht BN, Salomon B, Klatzman D, Pauwels RA: Dendritic cells are required for the development of chronic eosinophilic airway inflammation in response to inhaled antigen in sensitized mice. J Immunol 1998; 160:4090-4097.

22 Lanckacker EA, Robays LJ, Joos GF, Vermaelen KY: A new danger in the air: how pulmonary innate immunity copes with manmade airborne xenobiotics. J Innate Immun 2010;2:96-106.

23 Banchereau J, Briere F, Caux C, Davoust J, Lebecque S, Liu YJ, Pulendran B, Palucka K: Immunobiology of dendritic cells. Annu Rev Immunol 2000;18:767-811.

24 Lambrecht BN, De Veerman M, Coyle AJ, Gutierrez-Ramos JC, Thielemans K, Pauwels RA: Myeloid dendritic cells induce Th2 responses to inhaled antigen, leading to eosinophilic airway inflammation. J Clin Invest 2000;106:551-559.

25 Oriss TB, Ostroukhova M, Seguin-Devaux C, Dixon-McCarthy B, Stolz DB, Watkins SC, Pillemer B, Ray P, Ray A: Dynamics of dendritic cell phenotype and interactions with CD4(+) T cells in airway inflammation and tolerance. J Immunol 2005;174:854-863.

26 Vermaelen KY, Carro-Muino I, Lambrecht BN, Pauwels RA: Specific migratory dendritic cells rapidly transport antigen from the airways to the thoracic lymph nodes. J Exp Med 2001;193:51-60.

-27 Vermaelen K, Pauwels R: Pulmonary dendritic cells. Am J Respir Crit Care Med 2005; 172:530-551.

28 de Haar C, Hassing I, Bol M, Bleumink R, Pieters R: Ultrafine carbon black particles cause early airway inflammation and have adjuvant activity in a mouse allergic airway disease model. Toxicol Sci 2005;87:409-418.

29 de Haar C, Hassing I, Bol M, Bleumink R, Pieters R: Ultrafine but not fine particulate matter causes airway inflammation and allergic airway sensitization to co-administered antigen in mice. Clin Exp Allergy 2006; 36:1469-1479.

-30 de Haar C, Kool M, Hassing I, Bol M, Lambrecht BN, Pieters R: Lung dendritic cells are stimulated by ultrafine particles and play a key role in particle adjuvant activity. J Allergy Clin Immunol 2008;121:1246-1254.

31 de Heer HJ, Hammad H, Soullié T, Hijdra D, Vos N, Willart MA, Hoogsteden HC, Lambrecht BN: Essential role of lung plasmacytoid dendritic cells in preventing asthmatic reactions to harmless inhaled antigen. J Exp Med 2004;200:89-98.
32 Ohtani T, Nakagawa S, Kurosawa M, Mizuashi M, Ozawa M, Aiba S: Cellular basis of the role of diesel exhaust particles in inducing Th2-dominant response. J Immunol 2005;174:2412-2419.

-33 van Rijt LS, Jung S, Kleinjan A, Vos N, Willart M, Duez C, Hoogsteden HC, Lambrecht $\mathrm{BN}$ : In vivo depletion of lung CD11c (+) dendritic cells during allergen challenge abrogates the characteristic features of asthma. J Exp Med 2005;201:981-991.

- 34 Feau S, Facchinetti V, Granucci F, Citterio S, Jarrossay D, Seresini S, Protti MP, Lanzavecchia A, Ricciardi-Castagnoli P: Dendritic cell-derived IL-2 production is regulated by IL-15 in humans and in mice. Blood 2005; 105:697-702.

-35 Rothen-Rutishauser BM, Kiama SG, Gehr P. A three-dimensional cellular model of the human respiratory tract to study the interaction with particles. Am J Respir Cell Mol Biol 2005;32:281-289.

- 36 Robertson JM, Jensen PE, Evavold BD: DO11.10 and OT-II T cells recognize a C-terminal ovalbumin 323-339 epitope. J Immunol 2000; 164:4706-4712.

37 Dong W, Selgrade MJ, Gilmour MI: Systemic administration of Bordetella pertussis enhances pulmonary sensitization to house dust mite in juvenile rats. Toxicol Sci 2003; 72:113-121.

38 Stevens T, Krantz QT, Linak WP, Hester SA, Gilmour MI: Increased transcription of immune and metabolic pathways in naive and allergic mice exposed to diesel exhaust. Toxicol Sci 2008; 102:359-370.

39 Williams MA, Bauer S, Lu W, Guo J, Walter S, Bushnell TP, Lillehoj EP, Georas SN: Deletion of the mucin-like molecule Mucl enhances dendritic cell activation in response to toll-like receptor ligands. J Innate Immun 2010;2:123-143.

40 Blasius AL, Giurisat E, Cella M, Schreiber $\mathrm{RD}$, Shaw AS, Colonna M: Bone marrow stromal cell antigen 2 is a specific marker of type I IFN producing cells in the naïve mouse, but a promiscuous cell surface antigen following IFN stimulation. J Immunol 2006;177:3260-3265.

41 Hammad H, Lambrecht BN: Recent progress in the biology of airway dendritic cells and implications for understanding the regulation of asthmatic inflammation. J Allergy Clin Immunol 2006;118:331-336.

42 Li N, Hao M, Phalen RF, Hinds WC, Nel AE: Particulate air pollutants and asthma - a paradigm for the role of oxidative stress in PM-induced adverse health effects. Clin Immunol 2003;109:250-265.

43 Shi Y, Rock KL: Cell death releases endogenous adjuvants that selectively enhance immune surveillance of particulate antigens. Eur J Immunol 2002;32:155-162. 
44 Kouro T, Takatsu K: IL-5- and eosinophilmediated inflammation: from discovery to therapy. Int Immunol 2009;21:1303-1309.

-45 Percopo CM, Dyer KD, Killoran KE, Rosenberg HF: Isolation of human eosinophils: microbead method has no impact on IL-5 sustained viability. Exp Dermatol 2010;19: 467-469.

-46 Dubucquoi S, Desreumaux P, Janin A, Klein O, Goldman M, Tavernier J, Capron A, Capron $\mathrm{M}$ : Interleukin 5 synthesis by eosinophils: association with granules and immunoglobulin-dependent secretion. J Exp Med 1994;179:703-708.

47 Oberdorster G: Lung dosimetry - pulmonary clearance of inhaled particles. Aerosol Sci Technol 1993;18:279-289.

$\checkmark 48$ Horner AA: Regulation of aeroallergen immunity by the innate immune system: laboratory evidence for a new paradigm. J Innate Immun 2010;2:107-112.

-49 Ng N, Lam D, Paulus P, Batzer G, Horner AA: House dust extracts have both Th2 adjuvant and tolerogenic activities. J Allergy Clin Immunol 2006;117:1074-1081.

-50 Lam D, Ng N, Lee S, Batzer G, Horner AA: Airway house dust extract exposures modify allergen-induced airway hypersensitivity responses by TLR4-dependent and independent pathways. J Immunol 2008;181:29252932.

51 Diaz-Sanchez D, Riedl M: Diesel effects on human health: a question of stress? Am J Physiol Lung Cell Mol Physiol 2005; 289:L722-L723.

52 Holt PG, Schon-Hegrad MA, Oliver J, Holt BJ, McMenamin PG: A contiguous network of dendritic antigen-presenting cells within the respiratory epithelium. Int Arch Allergy Appl Immunol 1990;91:155-159.
53 Reibman J, Hsu Y, Chen LC, Bleck B, Gordon T: Airway epithelial cells release MIP-3alpha/CCL20 in response to cytokines and ambient particulate matter. Am J Respir Cell Mol Biol 2003;28:648-654.

54 Baulig A, Garlatti M, Bonvallot V, Marchand A, Barouki R, Marano F, Baeza-Squiban A: Involvement of reactive oxygen species in the metabolic pathways triggered by diesel exhaust particles in human airway epithelial cells. Am J Physiol Lung Cell Mol Physiol 2003;285:L671-L679.

55 Blanchet S, Ramgolam K, Baulig A, Marano F, Baeza-Squiban A: Fine particulate matter induces amphiregulin secretion by bronchial epithelial cells. Am J Respir Cell Mol Biol 2004;30:421-427.

56 Rumelhard M, Ramgolam K, Auger F, Dazy AC, Blanchet S, Marano F, Baeza-Squiban A: Effects of PM2.5 components in the release of amphiregulin by human airway epithelial cells. Toxicol Lett 2007;168:155-164.

57 Bleck B, Tse DB, Jaspers I, Curotto de Lafaille MA, Reibman J: Diesel exhaust particle-exposed human bronchial epithelial cells induce dendritic cell maturation. J Immunol 2006;176:7431-7437.

58 Bleck B, Tse DB, Curotto de Lafaille MA, Zhang F, Reibman J: Diesel exhaust particleexposed human bronchial epithelial cells induce dendritic cell maturation and polarization via thymic stromal lymphopoietin. J Clin Immunol 2008;28:147-156.

59 Kumagai Y, Arimoto T, Shinyashiki M, Shimojo N, Nakai Y, Yoshikawa T, Sagai M: Generation of reactive oxygen species during interaction of diesel exhaust particle components with NADPH-cytochrome P450 reductase and involvement of bioactivation in the DNA damage. Free Radic Biol Med 1997; 22:479-487.
60 Headley MB, Zhou B, Shih WX, Aye T, Comeau MR, Ziegler SF: TSLP conditions the lung immune environment for the generation of pathogenic innate and antigen-specific adaptive immune responses. J Immunol 2009;182:1641-1647.

61 Gehr P, Blank F, Rothen-Rutishauser VBM: Fate of inhaled particles after interaction with the lung surface. Paediatr Respir Rev 2006;7:S73-S75.

62 Muller L, Riediker M, Wick P, Mohr M, Gehr P, Rothen-Rutishauser B: Oxidative stress and inflammation response after nanoparticle exposure: differences between human lung cell monocultures and an advanced three-dimensional model of the human epithelial airways. J R Soc Interface 2010;7 (suppl 1):S27-S40.

63 Rescigno M, Urbano M, Valzasina B, Francolini M, Rotta G, Bonasio R, Granucci F, Kraehenbuhl JP, Ricciardi-Castagnoli P: Dendritic cells express tight junctions and penetrate gut eptithelial monolayers to sample bacteria. Nat Immunol 2001;2:361-367.

-64 Sung SS, Fu SM, Rose CE Jr, Gaskin F, Ju ST, Beaty SR: A major lung CD103 (alphaE)-beta7 integrin-positive epithelial dendritic cell population expressing Langerin and tight junction proteins. J Immunol 2006; 176: 2161-2172.

65 Braun A, Bewersdorff M, Lintelmann J, Matuschek G, Jakob T, Göttlicher M, Schober W, Buters JT, Behrendt H, Mempel M: Differential impact of diesel particle composition on pro-allergic dendritic cell function. Toxicol Sci 2010;113:85-94 